\title{
STRUCTURAL AND THERMAL CHARACTERISTICS OF HYBRID Co(II) PEROVSKITE CRYSTALS
}

\author{
S. Nithya ${ }^{1}$, K. Sugandhi ${ }^{1}$, P. Muthuraja ${ }^{2}$, S. Balachandar ${ }^{2}$, M. Dhandapani ${ }^{2}$ \\ and K. R. Aranganayagam, ${ }^{3, *}$ \\ ${ }^{1}$ Department of Physics, Kumaraguru College of Technology, Coimbatore (Tamil Nadu) India. \\ ${ }^{2}$ Department of Chemistry, Sri Ramakrishna Mission Vidyalaya College of Arts and Science, \\ Coimbatore (Tamil Nadu) India. \\ ${ }^{3}$ Department of Chemistry, Kumaraguru College of Technology, Coimbatore(Tamil Nadu) India. \\ *E-mail: aranganayagam@gmail.com
}

\begin{abstract}
The single crystals of benzyltributylammonium tetrachloro cobaltate (II) monohydrate (BTBA-Co) crystals were grown by slow evaporation solution growth technique at room temperature. The structural characteristics of the grown crystals were studied using Fourier transform infrared (FT-IR) spectroscopy, nuclear magnetic resonance (NMR $-{ }^{1} \mathrm{H}$ and ${ }^{13} \mathrm{C}$ ) spectroscopy, powder X-ray diffraction (PXRD) and unit cell parameter analyses. Phase transitions were studied through thermal analyses (TG-DTA and DSC).
\end{abstract}

Keywords: perovskite, hybrid crystals, XRD, thermal analyses

(C) RASĀYAN. All rights reserved

\section{INTRODUCTION}

Semiconducting metal halide perovskites have attracted considerable attention in optoelectronics, including photovoltaics and light emission, because of their excellent photophysical properties ${ }^{1-5}$. The organic-inorganic perovskite crystals are the materials used for solar cells, piezoelectric, dielectric, semiconducting and related potential applications ${ }^{6,7}$. Perovskite is the class of crystalline compounds described with the crystal structure of $\mathrm{A}_{2} \mathrm{BX}_{4}, \mathrm{ABX}_{3}$ etc., where $\mathrm{A}$ and $\mathrm{B}$ are the cations of organic and inorganic compounds, respectively and $\mathrm{X}$ is a halide. Recently, there are several methods were adopted to synthesize perovskite Single crystals like slow evaporation solution growth, slow cooling method, hydrothermal growth, gel growth and vapor growth. In this, slow evaporation solution growth technique is one of the simple and versatile routes to grow single crystals. Ono et al ${ }^{8}$ reported organometal halide perovskites as solar cells with the reasonable percentage of efficiency. Several researchers are reported this kind of crystals for alternate energies ${ }^{3,9,10}$.

The perovskite single crystals, for instance, provide an excellent platform to characterize a range of materials properties that could not be achieved by studying polycrystalline thin films. Hybrid perovskite single crystals exhibit superior luminescent performance than their thin film counterparts, enabling potential applications like large area display. Understanding the mechanism of the crystal growth provides insights into the growth process and enhancement of quality. The main objective of the present investigation is to the synthesis of benzyltributylammonium tetrachloro cobaltate (II) monohydrate single crystals. Also, the structural and thermal behavior of the grown crystals were studied using physiochemical characterizations.

\section{The Growth of Single Crystals (BTBA-Co)}

\section{EXPERIMENTAL}

The single crystals of benzyltributylammonium tetrachloro cobaltate (II) monohydrate (BTBA-Co) crystals are grown by slow evaporation of saturated aqueous solutions at room temperature. Aqueous solutions containing benzyl tributyl ammonium chloride and cobalt (II) chloride in 2:1 molar ratio,

Rasayan J. Chem., 11(3), 999-1003(2018)

http://dx.doi.org/10.31788/RJC.2018.1133030

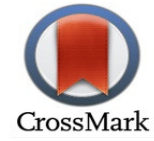


respectively, are prepared by using triply distilled water. The two solutions are mixed together well and the resulting solution is filtered through a Whatman No.4 filter paper into a clean beaker. The beaker is covered with aluminum foil. Care is taken to minimize the temperature gradient and mechanical shock. Bright and blue colored crystals of BTBA-Co are obtained within 35-45 days. The grown crystals are collected from the mother liquor by using well-cleaned forceps. The harvested crystals are recrystallized repeatedly to get crystal of good quality.

$$
2\left[\left(\mathrm{C}_{4} \mathrm{H}_{9}\right)_{3} \mathrm{~N}^{+}-\mathrm{CH}_{2}-\mathrm{C}_{6} \mathrm{H}_{5} \mathrm{Cl}^{-}\right]+\mathrm{CoCl}_{2} \underset{\text { Medium }}{\stackrel{\mathrm{H}_{2} \mathrm{O}}{\longrightarrow}} \stackrel{\left[\left(\mathrm{C}_{4} \mathrm{H}_{9}\right)_{3} \mathrm{~N}_{-}-\mathrm{CH}_{2}-\mathrm{C}_{6} \mathrm{H}_{5}\right]_{2} \mathrm{CoCl}_{4} \cdot \mathrm{H}_{2} \mathrm{O}}{\text { BTBA-Co }}
$$

Scheme-1: Formation of BTBA-Co single crystals

\section{Characterization Techniques}

The elemental analysis and FT-IR spectrum are carried out in ELEMENTAR VARIO EL III instrument and THERMO NICOLET AVTAR370 DTGS instrument, respectively. The NMR $\left({ }^{1} \mathrm{H}\right.$ and $\left.{ }^{13} \mathrm{C}\right)$ spectrum of BTBA-Co crystals are carried out in AMX 400 spectrometer. The simultaneous TG-DTA study is done on a NETZSCH STA 409C/CD thermal analyzer and the curves are obtained under a nitrogen atmosphere at a heating rate of $10^{\circ} \mathrm{C}$ per minute from room temperature to $800^{\circ} \mathrm{C}$. The cell parameters of grown crystals are recorded using BRUKER SMART APEX CCD single crystal diffractometer using MoK $\alpha$ radiation. A METTLER TOLEDO DSC822e instrument is used to record the low-temperature DSC curves for the samples at STIC, Cochin. The cooling run is carried out from $30^{\circ} \mathrm{C}$ to $-100^{\circ} \mathrm{C}$ and the heating run from $-100{ }^{\circ} \mathrm{C}$ to $30^{\circ} \mathrm{C}$ both at a rate of $10^{\circ} \mathrm{C}$ per minute under a nitrogen atmosphere.

\section{Elemental Analysis and FT IR Spectrum}

\section{RESULTS AND DISCUSSION}

The elemental analysis of dark blue coloured grown crystals shows that the compound contains carbon: $58.3 \%(59.15 \%)$, hydrogen: $10.4 \%(9.08 \%)$ and nitrogen: $3.7 \%(3.63 \%)$. The results indicate that both experimental and theoretical values (given in the brackets) are found to be in good agreement with each other and conform to the molecular formula of the compound $\left[\mathrm{C}_{6} \mathrm{H}_{5} \mathrm{CH}_{2}-\mathrm{N}-\left(\mathrm{C}_{4} \mathrm{H}_{9}\right)_{3}\right]_{2}\left[\mathrm{CoCl}_{4}\right] . \mathrm{H}_{2} \mathrm{O}$, BTBA-Co. The proposed crystal structure of BTBA-Co crystals are shown in Scheme-2.
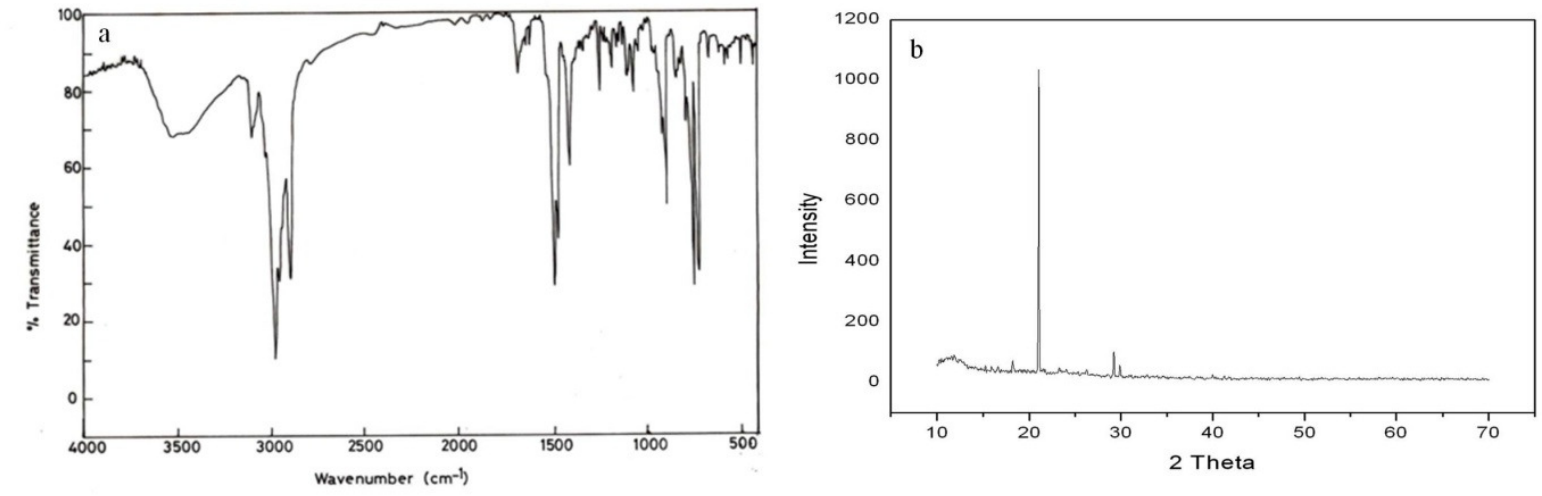

Fig.-1: (a) FTIR Spectrum and (b) XRD pattern of BTBA-Co Crystal

Further, the crystal formation can be confirmed through FTIR spectrum, shown in the Fig. -1 . The frequencies observed at $3491 \mathrm{~cm}^{-1}$ is due to the asymmetric $\mathrm{O}-\mathrm{H}$ stretching vibration mode. The absorption frequency at $3063 \mathrm{~cm}^{-1}$ is due to symmetric $\mathrm{O}-\mathrm{H}$ stretching vibration mode as well as C-H stretching of an aromatic nucleus. The frequencies at 2965 and $2875 \mathrm{~cm}^{-1}$ are due to the asymmetric and symmetric C-H stretching vibrational mode. The absorption frequencies at 1644, 1584, 1479, 1455, 1381 and $1213 \mathrm{~cm}^{-1}$ are due to $\mathrm{C}=\mathrm{C}$ stretching (skeletal) of phenyl nucleus, $\mathrm{CH}_{2}$ asymmetric bending, $\mathrm{CH}_{3}$ asymmetric bending, $\mathrm{CH}_{2}$ symmetric bending, $\mathrm{CH}_{3}$ symmetric bending and $\mathrm{C}-\mathrm{H}$ in-plane bending of phenyl ring respectively. The $\mathrm{CH}_{3}$ rocking, asymmetric C-C stretching, asymmetric $\mathrm{C}-\mathrm{N}$ stretching, $\mathrm{C}-\mathrm{H}$ 1000 
out-plane bending in phenyl ring, $\mathrm{CH}_{2}$ rocking mode, $\mathrm{C}$-C out-plane bending in aromatic nucleus and C$\mathrm{H}$ out-plane bending ode in mono substituted benzene ring observed at 1145, 1066, 1032, 868, 803, 726 and $702 \mathrm{~cm}^{-1}$ respectively. The C-N-C skeleton vibrational modes are observed at 627,546 and $459 \mathrm{~cm}^{-1}$.

\section{Powder X-Ray Diffraction and Cell Parameters}

The powder X-ray diffraction pattern of the BTBA-Co crystal is shown in the Fig.-1b. The sharp and well defined Bragg peaks in the powder XRD pattern confirm the crystallinity of the compound. The unit cell parameters of the crystal are determined by a least-squares technique using reflections. The compound crystallizes in triclinic system. The unit cell parameters for the crystal are $\mathrm{a}=11.24 \AA$; $\mathrm{b}=11.35 \AA$ and $\mathrm{c}$ $=17.26 \AA$. $\alpha=76.41^{\circ}, \beta=82.42^{\circ}$ and $\gamma=84.29^{\circ}(\alpha \neq \beta \neq \gamma)$. The volume of the unit cell is $2116 \AA^{3}$.

\section{NMR Spectroscopy}

The ${ }^{1} \mathrm{H}$ and ${ }^{13} \mathrm{C}$ NMR spectrum of BTBA-Co crystal are shown in the Fig.-2(a) and 2(b).

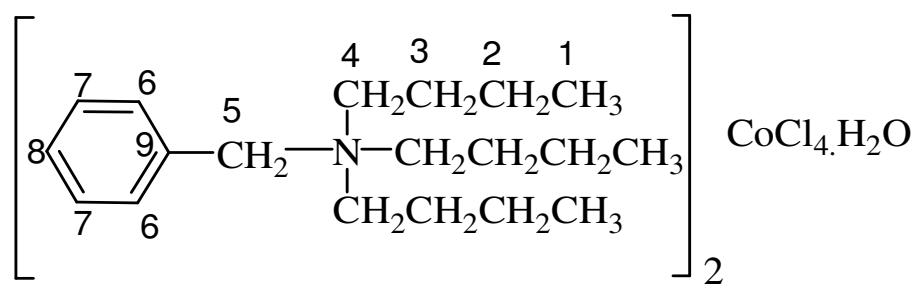

Scheme-2: Proposed Structure of BTBA-Co Single Crystals

In ${ }^{1} \mathrm{H}$ NMR (Fig.-2a), a singlet peak is observed at $\delta 7.5 \mathrm{ppm}$ which is due to the presence of aromatic protons. The two singlet peaks are observed at $\delta 4.9$ and $\delta 3.2 \mathrm{ppm}$ and are due to the water and methylene group protons which are attached with the aromatic ring respectively. A multiplet peak is observed at $\delta 1.4 \mathrm{ppm}$ which may due to the n-butyl group protons in the compound.

In ${ }^{13} \mathrm{C}$ NMR (Fig.-2b), a peak observed at $\delta 132.528 \mathrm{ppm}$ is due to the $\mathrm{C} 9$ carbon in the benzyl group. The peaks observed at $\delta 130.882, \delta 129.487$ and $\delta 127.382 \mathrm{ppm}$ are due to the C8, C7 and C6 carbons respectively. C5 methylene carbon peak is observed at $\delta 61.765 \mathrm{ppm}$. The butyl group carbons $\mathrm{C} 4, \mathrm{C} 3$, $\mathrm{C} 2$ and $\mathrm{C} 1$ are observed at $\delta 58.005, \delta 23.553, \delta 19.286$ and $\delta 13.160 \mathrm{ppm}$ respectively.

\section{Thermal Characteristics}

Thermogravimetry (TG) and differential thermal analysis (DTA) curves of BTBA-Co are shown in the Fig.-3a. When the compound is heated from 30 to $800^{\circ} \mathrm{C}$, it remains stable up to $170^{\circ} \mathrm{C}$. Decomposition is observed between $170{ }^{\circ} \mathrm{C}$ and $550{ }^{\circ} \mathrm{C}$ with weight loss of $61 \%$. The remaining $39 \%$ residue is unaffected even after heating up to $800{ }^{\circ} \mathrm{C}$. The above weight losses can be explained by formulating the following decomposition pattern.

$$
\begin{array}{cc}
{\left[\mathrm{C}_{6} \mathrm{H}_{5} \mathrm{CH}_{2}-\mathrm{N}-\left(\mathrm{C}_{4} \mathrm{H}_{9}\right)_{3}\right]_{2}\left[\mathrm{CoCl}_{4}\right] . \mathrm{H}_{2} \mathrm{O} \stackrel{{ }^{\circ} \mathrm{C}-550^{\circ} \mathrm{C}}{\longrightarrow}\left(\mathrm{C}_{7} \mathrm{H}_{7}\right)_{2} \mathrm{CoCl}_{2}+2 \mathrm{~N}\left(\mathrm{C}_{4} \mathrm{H}_{9}\right)_{3} \uparrow+\mathrm{Cl}_{2} \uparrow+\mathrm{H}_{2} \mathrm{O} \uparrow} \\
\text { Formula weight: } 771 & \text { Theoretical Loss }: 59.4 \% \\
& \text { Experimental Loss: } 61 \%
\end{array}
$$

Scheme-3: Thermal Decomposition Pattern of BTBA-Co Crystal.

The above pattern suggests the formation of the tropylium cobalt chloride as residue. Two moles as tributylammonia, 1 mole of chlorine gas and 1 mole of water are eliminated as a gaseous product at this temperature range. The proposed decomposition pattern amounts to a calculated weight loss of $59.4 \%$, whereas the experimental weight loss is $61 \%$. The weight loss difference of $1.6 \%$ is well within the experimental error limits. 

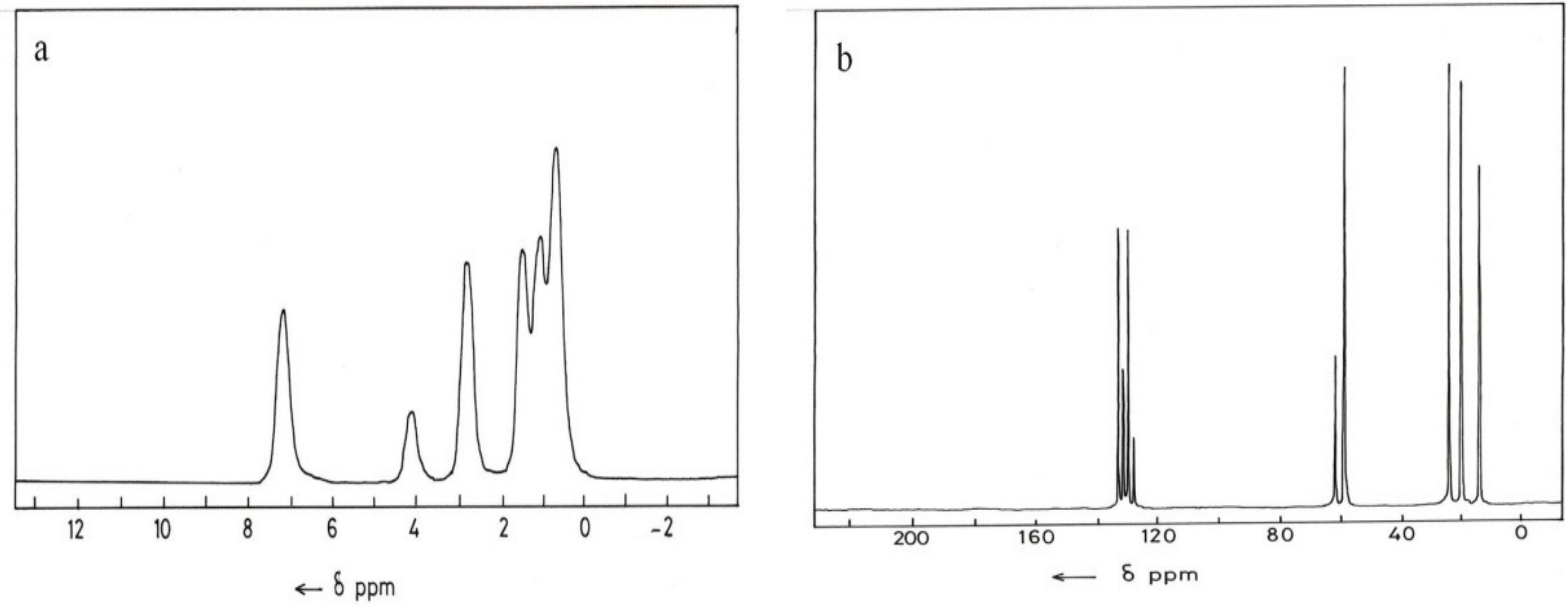

Fig.-2: (a) ${ }^{1} \mathrm{H}$ and (b) ${ }^{13} \mathrm{C}$ NMR Spectrum of BTBA-Co Crystal

In DTA thermogram, the broad endothermic peak is observed at $130^{\circ} \mathrm{C}$ shows the removal of surface moisture in the compound at this temperature. The broad band at $320^{\circ} \mathrm{C}$ is due to the first stage decomposition. The DTA results correlate well with the corresponding TG results. The low-temperature DSC curve is shown in the fig. $3 \mathrm{~b}$. No thermal anomalies are observed in both cooling and heating runs. It clearly shows that there is no structural phase transition in the compound at temperatures below room temperature.
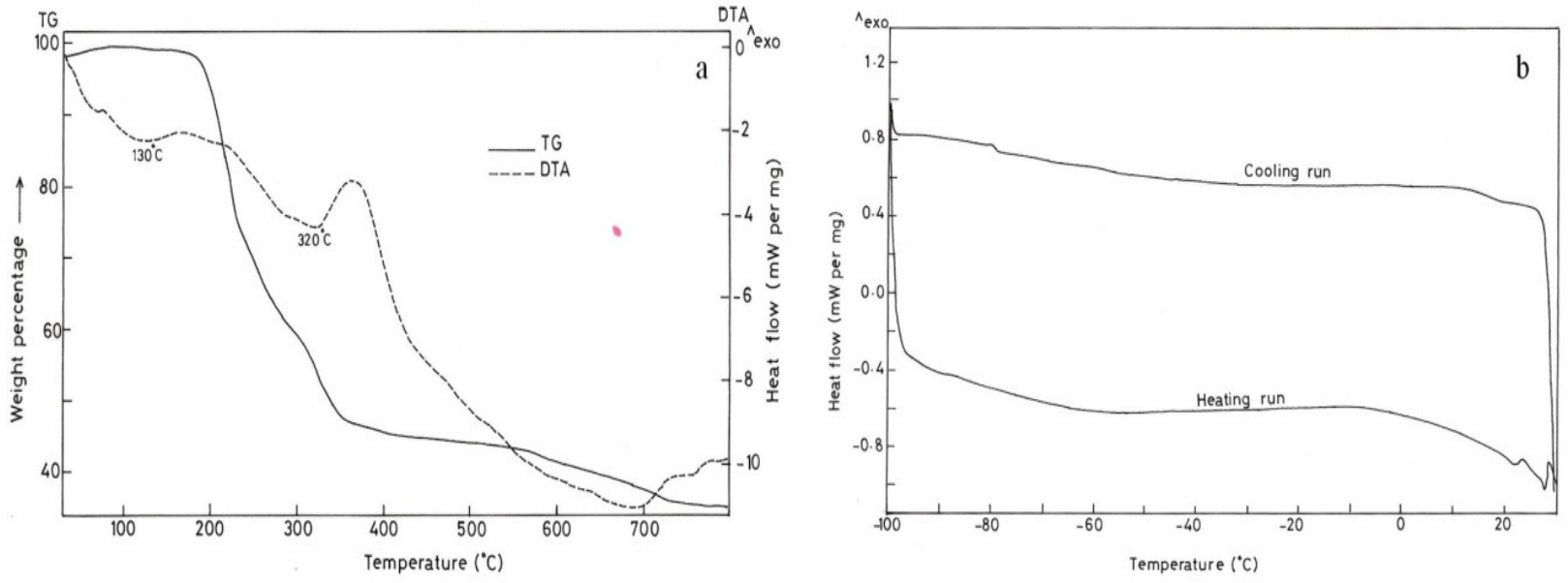

Fig.-3: (a) TG-DTA and (b) DSC Curves of BTBA-Co Crystal

\section{CONCLUSION}

BTBA-Co single crystal with good optical quality is grown using slow evaporation technique at room temperature. XRD studies reveal that the grown crystal belongs to a triclinic system. From the elemental composition results, the presence of carbon, hydrogen, and nitrogen are exactly coincidence with the theoretical molecular formula of the compound.

The various functional groups present in the BTBA-Co crystal is evaluated using FT-IR studies. Further, the molecular structure of the complex crystal was analyzed using ${ }^{1} \mathrm{H}$ and ${ }^{13} \mathrm{C}$ NMR spectroscopy studies and TG-DTA analyses show BTBA-Co is thermally stable up to $130^{\circ} \mathrm{C}$.

\section{REFERENCES}

1. J. Burschka, N. Pellet, S.-J. Moon, R. Humphry-Baker, P. Gao, M.K. Nazeeruddin and M. Grätzel, Nature, 499, 316 (2013), DOI: 10.1038/nature 12340 
2. M.M. Lee, J. Teuscher, T. Miyasaka, T. N. Murakami, H.J. Snaith, Science, 338, 643 (2012), DOI: 10.1126/science. 1228604

3. N. J. Jeon, J. H. Noh, W. S. Yang, Y. C. Kim, S. Ryu, J. Seo, S. I. Seok, Nature, 517, 476 (2015), DOI: 10.1038 /nature 14133

4. W. S. Yang, J. H. Noh, N. J. Jeon, Y. C. Kim, S. Ryu, J. Seo, S. I. Seok, Science, 348, 1234 (2015), DOI: $10.1126 /$ science.aaa9272

5. Z. K. Tan, R. S. Moghaddam, M. L. Lai, P. Docampo, R. Higler, F. Deschler, M. Price, A. Sadhanala, L. M. Pazos, D. Credgington, F. Hanusch, T. Bein, H. J. Snaith, R. H. Friend, Nat. Nanotechnol., 9, 687(2014), DOI: 10.1038/nnano.2014.149

6. R. F. Service, Science, 344, 6183 (2014), DOI: 10.1126/science.344.6183.458

7. P. Umari, E. Mosconi, and F. De Angelis, Scientific Reports, 4, 4467 (2014), DOI:10.1038/srep04467

8. M. Dhandapani, K. Sugandhi, S. Nithya, P. Muthuraja, S. Balachandar and K.R. Aranganayagam, AIP Conf. Proc., 1953, 070017-1 (2018), DOI: 10.1063/1.5032795

9. H. A. Abbas, R. Kottokkaran, B. Ganapathy, M. Samiee, L. Zhang, A. Kitahara, M. Noack and V. L. Dalal, APL Mater., 3, 016105 (2015), DOI: 10.1063/1.4905932

10. A. Ng, Z. Ren, Q. Shen, S. H. Cheung, H. C. Gokkaya, G. Bai, J. Wang, L. Yang, S. K. So, A. B. Djurisic, W. W.-f. Leung, J. Hao, W. K. Chan and C. Surya, J. Mater. Chem. A, 3, 9223 (2015), DOI:10.1039/C4TA05070C

[RJC-3030/2018] 